\title{
GAMBARAN PENGGUNAAN INTRA UTERINE DEVICE (IUD) PADA WUS (WANITA USIA SUBUR) DI KELURAHAN CILENDEK TIMUR KECAMATAN BOGOR BARAT TAHUN 2019
}

\author{
Yusti Hanifah', Fenti Dewi Pertiwi², Tika Noor Prastia ${ }^{3}$ \\ ${ }^{1}$ Yusti Hanifah, Konsentrasi Kesehatan Ibu dan Anak, Program Studi Kesehatan Masyarakat, Fakultas Ilmu \\ Kesehatan, Universitas Ibn Khaldun JL. KH. Soleh Iskandar KM2 Kedung Badak Tanah Sareal Bogor 16162. \\ Email : yustihanifah12@gmail.com \\ ${ }^{2}$ Fenti Dewi Pertiwi , Program Studi Kesehatan Masyarakat, Fakultas Ilmu Kesehatan, Universitas Ibn Khaldun JL. \\ KH. Soleh Iskandar KM2 Kedung Badak Tanah Sareal Bogor 16162.Email :fenti.dewi.pertiwi@gmail.com \\ ${ }^{3}$ Tika Noor Prastia, Program Studi Kesehatan Masyarakat, Fakultas Ilmu Kesehatan, Universitas Ibn Khaldun JL. \\ KH. Soleh Iskandar KM2 Kedung Badak Tanah Sareal Bogor 16162. Email : tikaprastia9@gmail.com
}

\begin{abstract}
Abstrak
Upaya yang dilakukan pemerintah dalam menekan laju pertumbuhan penduduk yaitu dengan menggalakan program Keluarga Berencana untuk mewujudkan penduduk tumbuh seimbang berkualitas. Tujuan dari penelitian ini adalah untuk mengetahui Gambaran Penggunaan Intra Uterine Device (IUD) pada Wanita Usia Subur (WUS) di Kelurahan Cilendek Timur Kecamatan Bogor Barat tahun 2019. Rancangan penelitian ini merupakan penelitian kualitatif deskriptif dengan menggunakan desain Rapid Assesment Procedure (RAP). Dengan jumlah populasi sebanyak 18 informan yaitu 4 informan yang menggunakan (IUD), 4 informan non-IUD, dan 10 orang informan kunci, data primer dikumpulkan dengan cara observasi dan melakukan wawancara mendalam kepada informan dan informan kunci. Hasil penelitian menunjukan 4 WUS yang menggunkaan IUD memiliki pengetahuan cukup mengenai kontrasepsi IUD, 4 WUS bersikap positif terhadap kontrasepsi IUD, 8 informan IUD maupun non-IUD mendapat dukungan dari suami, 7 dari 8 WUS di berikan tanggapan yang postif oleh suami, 8 WUS pernah mendapatkan, 1 WUS non-IUD yang mendapatkan informasi dari tetangga sehingga memeberikan dampak negatif terhadap pengetahua WUS. Kesimpulan dalam penelitian ini adalah Pengetahuan WUS yang menggunakan IUD lebih baik dari WUS yang non-IUD, sikap WUS peserta IUD bersikap positif terhadap kontrasepsi IUD di bandingkan dengan WUS bukan peserta IUD, 7 dari 8 WUS pernah mendapatkan informasi mengenai IUD dari pelayanan kesehata, dan hanya 1 WUS yang mendapatkan informasi dari tetangga.
\end{abstract}

Kata kunci : Intra Uterine Device (IUD), KB, WUS.

\section{PENDAHULUAN}

Tingginya angka kelahiran di Indonesia merupakan salah satu masalah besar dan memerlukan perhatian khusus dalam penanganannya, laju peningkatan penduduk pada tahun 2015 sebesar 255.461.686 jiwa, jumlah penduduk indonesia berada pada urutan keempat (4) terbesar setelah Cina, India, Amerika Serikat ( Profil Kesehatan Indonesia, 2015 ). Oleh karena itu upaya menekankan jumlah penduduk dengan menggalakan program Keluarga Berencana (BPS, 2013). 
Upaya yang dilaksaakan dalam program KB adalah melalui penggunaan alat kontrasepsi. Berdasarkan data World Health Statistics tahun 2016. Penggunaan kontrasepsi telah meningkat di banyak bagian dunia, terutama di Asia dan Amerika Latin, tetapi terus menjadi rendah di sub-Sahara Afrika. Secara global, penggunaan kontrasepsi modern telah meningkat sedikit, dari 54\% pada tahun 1990 menjadi 57,4\% pada tahun 2015.

Berdasarkan hasil data Badan Kependudukan dan Keluarga Berencana Nasional (BKKBN) Indonesia pada tahun 2013 mendapatkan, pengguna Kontrasepsi Suntik 4.128.115 peserta (48,56\%), pil 2.261.480 peserta (26,60\%), implant 784.215 peserta $(9,23 \%)$, komdom 517.638 peserta (6,09\%). Alat Kontrasepsi Dalam Rahim (AKDR) 658.632 peserta (7,75\%), MOW 128.793 peserta (1,52\%), MOP 21.374 peserta (0,25\%), dari data diatas dapat kita lihat metode kontrasepsi suntik adalah metode yang terbanyak digunakan (Kemenkes RI, 2015).

Salah satu maslah utama yang dihadapi saat ini adalah masih rendahnya penggunaan KB Intra Uterine Device (IUD), sedangkan kecenderungan penggunaan jenis $\mathrm{KB}$ lainnya meningkat. Angka penggunaan IUD yang masih rendah dapat disebabkan oleh berbagai faktor yang menyebabkan rendahnya penggunaan metode Kontrasepsi IUD ini antara lain: Faktor Internal: Pengalaman, takut, Pengetahuan/pemahaman yang salah satunya IUD, pendidikan Wanita Usia Subur (WUS) yang rendah, malu dan risih, adanya penyakit, persepsi tentang IUD. Faktor Eksternal: prosedur pemasangan IUD yang rumit, pengaruh dan pengalaman aseptor IUD lainya, sosial budaya dan ekonomi serta pekerjaan (Ayu, 2012).

Di Jawa Barat pengguna IUD masih rendah dibandingkan dengan suntuik. Hal ini terlihat dari data pemakaian kontrasepsi secara keseluruhan yaitu suntik 57.75\%, pil 19.37\%, implan 8,6\%, IUD 6,40\%, kondom 5,4\%, MOW 2,61\%, dan MOP 0,47\%. Di Kabupaten Bandung Kontrasepsi yang digunakan dengan rincian suntik 61,13\%, pil 14,03\%, IUD 10,25\%, implan 7,24\%, kondom 5,48\%, MOW 1,44\%, MOP 0,43\% dengan jumlah PUS 22,378 serta peserta KB Aktif 16,241. (BKKBN Provinsi Jawa Barat, November 2010). Hasil data yang didapatkan, penggunaan KB kontrasepsi Hormonal Lebih tinggi dari pada Kontrasepsi Non Hormonal dengan jumlah sebesar 86,78\% (Depkes RI, 2008).

IUD adalah alat kontrasepsi yang dimasukan kedalam rahim terbuat dari pelastik yang kecil dan fleksibel, yang dipasang oleh bidan atau dokter yang terlatih dan berpengalaman. IUD sangat efektif untuk mencegah kehamilan sampai dengan 10 tahun. Cara kerja IUD yaitu menghambat sperma untuk masuk ke seluruh sel telur. Mencegah sperma dan sel telur bertemu sehingga tidak terjadi kehamilan. Membuat sperma sulit kedalam alat reproduksi perempuan dan mengurangi kemampuan sperma untuk melakukan pembuahan (SKATA, 2018).

Pencapaian peserta KB aktif di Kota Bogor, dimana Kota Bogor ini memiliki 6 Kecamatan yaitu Kecamatan Bogor Selatan, Bogor Timur, Bogor Tengah, Bogor Barat, Bogor Utara dan Tanah Sareal, menurut Dinas Pengendalian Penduduk dan Keluarga Berencana (DPPKB), cakupan target pencapaian KB aktif pada tahun 2018 yaitu 118.815 orang (76,35\%). Bogor Barat menempati 2 (dua) terendah dari penggunaan metode KB Intra Uterine Device (IUD) yaitu sebesar 4,704 orang dari 16 Kelurahan yaitu, Menteng, Sindang Barang, Bubulak, Margajaya, Balumbang Jaya, Situ Gede, Semplak Cilendek Barat, Cilendek Timur, Curug Mekar, Curug, Pasir Jaya, Pasir Kuda, Pasir Mulya, Gunung Batu dan Loji.

Berdasarkan data DPPKB jumlah WUS (Wanita Usia Subur). Menurut BKKBN (2015) 
adalah wanita yang berumur 15-49 tahun baik yang berstatus kawin maupun yang belum kawin atau janda. Dalam penggunaan alat Kontrasepsi IUD menyatakan bahwa Kelurahan Cilendek Timur merupakan Wilayah yang memilik aseptor terendah yaitu 4 orang $(12,5 \%)$ (DPPKB, 2018).

Berdasarkan uraian diatas penulis sangat tertarik untuk mengkaji lebih dalam lagi tentang permasalahan penggunaan alat kontrasepsi terrutama kontrasepsi intra uterine device (IUD). Terkhusus di Bogor bagian Barat tepatnya di Kelurahan Cilendek Timur. Maka dari itu penulis melakukan penelitian dan pembahasan terhadap pokok masalah yang diangkat, yang hasilnya dituangkan dalam suatu tulisan ilmiah dalam bentuk skripsi dengan judul : "Gambaran Penggunaan intra uterine device (IUD) pada Wanita Usia Subur (WUS) di Kelurahan Cilendek Timur Kecamatan Bogor Barat".

\section{METODE}

Penelitian ini menggunakan metode kualitatif dengan jenis rancangan penelitian Rapaid Assesment Procedure (RAP) yaitu penelitian yang dilakukan dalam kurun waktu yang singkat. Penelitian ini bertujuan untuk mengetahui Gambaran Penggunaan Intra uterine device (IUD) pada Wanita Usia Subur (WUS) di Kelurahan Cilendek Timur Kecamatan Bogor Barat melalui wawancara mendalam kepada informan yang terlibat dalam pelaksanaan pemakaian alat kontrasepsi IUD.

Penelitian ini dilaksanakan pada Bulan Januari-Maret tahun 2019 di Kelurahan Cilendek Timur Kecamatan Bogor Barat. Pemilihan lokasi penelitian disebabkan karena Kelurahan Cilendek Timur ini masih rendah penggunaan alat kontrasepsi intra uterine device (IUD) di kalangan Wanita Usia Subur (WUS) yang sudah menikah dibandingkan kelurahan lainnya yang ada di Kecamatan Bogor Barat. Populasi dalam penelitian ini adalah seluruh Wanita Usia Subur (WUS) yang berusia dari 15-49 tahun, yang ada di Kelurahan Cilendek Timur Kecamatan Bogor Barat yang berjumlah 2,486 informan.

Sampel dalam penelitian ini adalah wanita usia subur yang berusia 24 - 49 tahun yang ada di Kelurahan Cilendek Timur, Bogor Barat yang sudah menikah dengan jumlah 8 informan yaitu 4 informan yang menggunakan kontrasepsi IUD, 4 informan non-IUD, dan 10 informan kunci yaitu 8 informan kunci suami, 1 informan kunci PLKB Kelurahan dan 1 informan kunci KORLAP PKB Kecamatan Bogor Barat. Jadi total keseluruhan informan dalam penelitian ini adalah 18 informan.

Variabel dalam penelitian ini adalah penggunaan intra uterine device (IUD), pengetahun, sikap, sumber informasi dan dukungan suami. Data yang digunakan dalam penelitian ini adalah data primer dan data skunder dan observasi, data primer melalui pengumpulan data dengan cara wawancara mendalam langsung dengan informan yaitu wanita usia subur (WUS) yang menggunakan kontrasepsi IUD dan non-IUD di Kelurahan Cilendek Timur. Data skunder berupa laporan cakupan catatan data akseptor yang menggunakan kontrasepsi IUD dari KORLAP PKB dan PLKB Kelurahan. Dalam penelitian ini observasi meliputi melihat dan mencatat jumlah dan taraf aktivitas tertentu yang ada hubungannya dengan masalah yang diteliti, hal yang diperhatikan. Hal yang diperhatikan dalam penelitian ini adalah mengenai pengetahuan ibu terhadap metode kontrasepsi IUD, sikap ibu terhadap penggunaan alat kontrasepsi IUD, sumber informasi yang di dapat, serta dukungan suami terhadap istri yang 
menggunkan alat kontrasepsi IUD.

Instrument yang digunakan dalam penelitian ini adalah pedoman wawancara mendalam,yang berisi pertanyaan pertanyaan yang berhubungan dengan Gambaran penggunaan intra uterine device (IUD) tap recorder (perekam suara) untuk merekam jalannya wawancara. Alat perekam ini berupa tape recorder yaitu handphone,, dan dokumentasi, dalam penelitian ini menggunakan dokumnetasi berupa tape recorder, camera, data skunder dari PLKB Kelurahan dan PLKB Kecamatan, foto atau video untuk mendukung perolehan informasi secara jelas dan konkrit agar dijadikan hasil penelitian.

Pengumpulan data yang dilakukan adalah pengumpulan data primer yaitu peneliti mengambil data secara langsung dilapangan dengan cara wawancara mendalam. Wawancara dilakukan dengan cara mendatangi langsung rumah informan yang menggunakan sudah menggunakan kontrasepsi IUD dan tidak menggunakan kontrsepsi IUD sesuai dengan data laporan yang ada di PLKB Kelurahan.

Sebelum dilakukan pengambilan data atau wawancara kepada informan, terlebih dahulu dimintakan persetujuannya (informed consent) apabila informan tidak bersedia diwawancarai atau memberikan informasi adalah hak informan, dan tidak dilanjutkan pengambilan data atau wawancaranya. Isi informed consentatau lembar persetujuan diantaranya persetujuan informan untuk di wawancara, persetujuan informan untuk di rekam, ersetujuan informan untuk di dokumentasi (diambil foto, direkam saat wawancara dan dibuatkan transkip dan hasil wawancara dan persetujuan informan untuk di publikasikan dalam bentuk karya ilmiah. Saat dilakukannya wawancara ini peneliti dibantu oleh kader dan PLKB Kelurana Cilendek Timur.

\section{HASIL}

Berdasarkan hasil observasi lapangan di Kelurahan Cilendek Timur Kecamatan Bogor Barat yang terdiri dari $12 \mathrm{RW}$, terdapat 2.486 wanita usia subur, yang dijadikan sampel dalam penelitian ini hanya Wanita Usia Subur di RW 05, 02 dan RW 01, yaitu : RW 05 terdapat 1 informan Wanita Usia Subur pengguna IUD, RW 02 terdapat 4 informan Wanita Usia Subur yaitu 2 yang menggunakan kontrasepsi IUD dan 2 yang non-IUD diantaranya pil, dan di RW 01 terdapat 3 orang informan Wanita Usia Subur yaitu 1 yang menggunakan kontrasepsi IUD, 1 suntik dan 1 steril, sehingga informan yang digunakan sebanayak 8 informan.

Berdasarkan hasil validitas data yang menggunakan teknik triangulasi pada penelitian ini menggunakan triangulasi sumber, data, dan triangulasi metode. Trangulasi Data ini menggunakan data yang sebelumnya didapat dari dinas pegendalian penduduk dan keluarga berencana dan laporan dari KORLAP PKB Kecamatan Bogor Barat, kemudian dipastikan dengan mendatangi Petugas PLKB Kelurahan untuk memperoleh data yang lebih Spesifik, triangulasi sumber yaitu melakukan cross check data dengan fakta dari sumber lain yaitu keluarga/ Suami, KORLAP PKB dan petugas PLKB yang berfungsi sebagai informan kunci, dan Triangulasi metode dilakukan dengan cara menggunakan beberapa metode dalam pengumpulan data. Selain menggunakan metode wawancara mendalam terhadap informan juga dilakukan observasi untuk memastikan kondisi sebenarnya. Dari data-data yang sudah dikumpulkan baik data primer maupun skunder yang telah diringkas dalam bentuk matriks di peroleh hasil. 


\section{Hasil Penelitian Gambaran Penggunaan Intra Uterine Device (IUD) pada Wanita Usia Subur (WUS) di Kelurahan Cilendek Timur Kecamatan Bogor Barat}

\section{Pengetahuan}

Dari hasil wawancara dengan informan di dapatkan 4 informan IUD, dan 4 informan non-IUD, mengetahui definisi keluarga berencana. 8 informan yang menggunakan IUD maupun NonIUD menjawab definisi keluarga berencana adalah 2 anak cukup.

"emmmmm.... Keluarga yang ini yah,, emmm keluarga yang merencanakan anak dua yah hehehhee" ( Suntik, B2, 36 tahun).

8 informan 4 (empat) informan IUD, 4 (empat) no-IUD mengetahui kontrasepsi IUD akan tetapi hanya 3 dari 8 informan yang mengetahui definisi dari intra uterine device (IUD). Mereka mejawab bahwa iud adalah kontrasepsi yang dimasukan kedalam Rahim meskipun jawaban yang diberikan belum sempurna

"iyaa ibu mengetahui mengetahui, yang dimasukin ke dalam rahim ituu, emm kedalem vagina" (IUD,A1, 40 tahun)

Namun 1 (satu) informan yang bukan peserta IUD mengetahui kontrasepsi IUD tetapi menjawab lupa saat ditanyakan definisi mengenai IUD.

7 dari 8 informan baik informan peserta IUD mupun bukan peserta IUD mengetahui berapa jangka waktu penggunaan IUD, rata-rata jawaban yang diberikan 8-10 tahun.

"5 tahun, 8 tahun, kalo yang saya gunakan sekarang 8 tahun" (IUD, A1, 40 tahun).

Namun 1 informan yang bukan peserta IUD menjawab lupa saat ditanyakan jangka waktu pemakaian IUD.

8 informan diantaranya 4 (empat) informan IUD, 4 (empat) informan non-IUD mengetahui dan menjawab dengan jawaban sesuai dengan persepsi mereka yaitu diantaranya menstruasi lancer, dan tidak perlu ke bidanke bidan.

"oohhh, keuntungnnya yaaa tidak usah apa emmm tiap bulan ke ini gitu yaah ke bidan kb apa segala mecem jadi enak yah nyantai kata kita mah,"

"mensnya lancer, emmm itu aja sih karna kebanyakan ibu pengen mensnya lancer, banyak lah gitu" (IUD, A3, 30 tahun)

(4 informan) yang menggunakan kontrasepsi IUD, dua diantaranya menjawab efek samping yang dirasakan, dengan jawaban yang mereka berikan terasa saat berhubungan intim, dan kecapean

"kalo berhubungan yah suka ke ini, kerasa gituu,, si bapaknya suka kerasa jugaa gituuu" (IUD, A1, 40 tahun)

Lain halnya dengan 2 informan yang menggunakan kontrasepsi IUD mereka tidak merasakan efek samping yang di timbulkan saat menggunakan kontrasepsi IUD.

"ga ada deh yaaah selama pake iud saya mah ga adaa, mens juga biasa ajaa, seminggu 


\section{teh lancar lancar aja" ( IUD, A2, 47 tahun)}

Sementara itu 4 (empat) informan non-IUD, memberikan jawaban sesuai yang mereka dengar, karena tidak semua dari mereka pernah menggunakan kontrasepsi IUD

"oh kalo kecapean suka sakit ini di mulut rahim, suka sakit aja, apalagi kalo mau mens, suka nyeri nyeri jugaaa, kan dulu saya juga pernah spiral" (Suntik, B2, 36 tahun).

\section{Sikap}

Dari hasil wawancara dengan informan di dapatkan 8 informan yaitu 4 (empat) informan IUD, 4 (empat) informan non-IUD, menanggapi program pemerintah mengenai 2 anak cukup dengan sikap yang positif dan mendukung. Yang berarti hampir seluruh informan setuju dengan program pemerintah tersebut.

"kalo saya sih dengan program pemerintah yang seperti itu yaa setuju setuju saja gituu,, karna kan kalo kebanyakan anak yaa ntar giman yaah ribet jugaaa" (IUD, A3, 30 tahun).

8 informan yaitu 4 (empat) informan IUD,dan

4 (empat) informan non- IUD, mengetahui kontrasepsi yang digunakannya saat ini, lalu saat 8 (delapan) informan di tanyakan perihal alasana menggunakan kontrasepsi yang di pilih sekarang mereka menjawab karena aman.

"itu kan yaaah iud, karna yaaa mungkin aman, efek samping ke badan juga engga bikin sakit, ga bikin gemuk gitu aja, di pakenya aman lah sampe tahunan juga gitu kan efeknya juga "(IUD, A2, 47 tahun)

4 dari 8 informan yang sudah menggunakan kontrasepsi IUD memberikan alasan tidak ingin beralih ke kontraspsi lain karena untuk kesehatan dirinya dan karena lebih praktis nyaman, dan gratis.

"engga, soalnya kan sekarang udah 47 tahun juga yah, mungkin sampai apah sampai ga haid mungkin bisa di buka yaah, karna sekarang lagi haid jadi blm bisa dibuka, udah cocok juga yaah,, kalo kata kit aman simpel lah yah, ada yg gratis juga kan yah dari pemerintah, jadi ibu nyari yg enak dan aman yah" (IUD, A2, 47 tahun).

Adapun 4 (empat) informan non-IUD, memebrikan jawaban menolak untuk berlih ke kontrasepsi lain seperti IUD karena takut mencoba, tidak diizinkan suami, dan tetap menggunakan kontrasepsi yang sekarang karena alasan sudah cocok dan nyaman.

"udah deh di pil aja deh, udah cocok, soalnya kernah suntik ga cocok ke saya nya trus IUD juga saya takut heehe " (Pil, B1, 42 tahun).

Lain hal nya dengan 1 informan non-IUD (steril), alasan tidak ingin berganti kontrasepsi lain karena sudah menggunakan kontrasepsi steril.

\section{Dukungan Suami}

8 informan yaitu 4 (empat) iforman IUD, dan 4 (empat) informan non-IUD, di dukung oleh suami dengan memberikan dukungan yang beragam, seperti, mengingatkan, mengantar, 
membiayai, serta memotivasi istri. "mendukung sih yahh, mendukungnya kaya nganterin pas pemasangan saya mau IUD" (IUD, A1, 40 tahun).

"iyaa kalo suami saya memberikan yaaa jadi dia tuh memotivasi, jadi ngasih arahan kalau emng gamau dulu punya anak yaudah kita kb dulu aja, tapi kalo emng mau yaudah silahkan" (IUD, A4, 24 tahun).

2 dari 8 jawaban informan yang memakai kontrasepsi IUD memeberikan jawaban bahwa suami informan mendukung dengan tanggapan yang diberikan cukup baik.

"tidak apa-apa aman aman aja katanya pokonya selagi ituuu saya nya ga apa apa mah suami mendukung " (IUD, A3, 30

Beda halnya dengan 4 informan non-IUD, memberikan jawaban mengenai tanggapan suami terhadap kontrasepsi yang digunakan adalah dengan memebrikan tanggapan yang positif terhadap kontrasepsi yang digunakan informan.

"tergantung enak di saya nya gituu, saya nya enak ga using ga apa ga ada keluhan lain yaa ga apa apa "(Pil, B1, 42 tahun).

\section{Sumber Informasi}

Dari hasil wawancara dengan informan didapatkan hasil bahwa 8 informan yaitu 4 (empat) informan IUD, dan 4 (empat) informan non-IUD, sudah pernah mendapatkan informasi tersebut dari bidan, PLKB, kader, dari pelayanan kesehatan juga seperti puskesmas dan posyandu.

"suka dari puskesmas suka dikasih dari desa juga, dari puskesmas juga, dari bidan kader juga, penyuluhan kaya dikasih tau kb yg gratis gtuu kaya spriral yg ibu pakai sekarang" (IUD, A2, 47 tahun).

7 dari 8 informan yang memakai alat kontrasepsi IUD maupun non-IUD menanggapi informasi tersebut dengan positif, jelas, bagus dan dapat di mengerti.

"kalo tanggapan informasinya jelas sih yah, kaya gituu" (IUD, A1, 40 tahun).

Beda hal nya dengan jawaban informan non- IUD, dikarenakan informasi yang di dapat bersumber dari lingkungan sekitar seperti teman dekat, tanggapan mengenai informasi IUD pun menjadi negative atau berbeda, dan sedikit menimbulkan rasa takut terhadap informasi yang di dapat .

"sebelum ini saya kan di tawarinya IUD yaaa mungkin ada temen yaaa temen saya itu curhatnya aga sedikit negative jadi saya kebawa baper gitu ngedenger dia" (Steril, B3, 38 tahun).

\section{PEMBAHASAN}

\section{Faktor predisposisi pengetahuan}

Beradasarkan hasil wawancara dengan informan, didapatkan bahwa 4 informan yang menggunakan kontrasepi IUD 4 informan non- IUD, keluarga berencana adalah 2 (dua) anak saja cukup, 8 (delapan) informan yaitu 4 informan menggunakan IUD dan 4 informan non-IUD 
sudah mengetahui kontrasepsi IUD, 7 (tujuh) dari 8 (delapan) informan menjawab dengan jawaban 8 dan 10 tahun, 1 (satu) informan menjawab tidak tahu, 4 dari 8 informan menjawab menstruasi lancer, serta tidak perlu tiap bulan pergi ke bidan untuk suntik, 6 (enam) dari 8 informan yaitu 4 informan yang menggunakan IUD dan 4 informan non- IUD menjawab efek samping dari kontrasepsi IUD yaitu terasa sakit, 2 informan menjawab tidak mengrtahui.

Menurut penelitian Mizna Sabila (2016) menyatakan bahwa hampir semua informan yang menggunakan kontrasepsi IUD mengetahui pemasangan alat kontrasepsi IUD di pasang di dalam rahim, dan hanya satu informan yang tidak tahu pada bagian mana dipasangkannya kontrasepsi IUD. Dengan demikian semua informan mengetahui bahwa alat kontrasepsi IUD di pasang di mulut rahim.

Hal ini berkaitan dengan hasil wawancara bersama 8 informan yaitu 4 WUS yang menggunakan IUD dan 4 WUS non-IUD, 6 dari 8 informan mengetahui definisi KB, definisi IUD, jangka waktu pemakaian IUD, efek samping serta keuntungan IUD, dan hanya ada 2 informan non-IUD yang tidak mengetahui, definisi IUD, jangka waktu pemakaina IUD, dan efek samping IUD.

\section{Sikap}

Berdasarkan hasil wawancara dengan informan didapatkan sebanyak 8 (delapan) informan yaitu 4 informan yang menggunakan IUD dan 4 informan non- IUD, di tanyakan pendapat mengenai program pemerintah bahwa 2 anak cukup, 8 (delapan) informan memberikan jawaban setuju dengan program tersebut namun 4 dari 8 informan memberikan alasan nya setuju, adapun 1 jawaban informan sesuai yang diharapkan yaitu untuk mengurangi angka kematian bayi dan anak, Selanjutnya 8 informan diberikan pertanyaan mengenai kontrasepsi yang digunakan saat ini, ke-8 informan yaitu 4 informan yang menggunakan IUD dan 4 informan non- IUD, menjawab dan mengetahui metode kontrasepsi yang digunakannya sekarang, ke-8 informan yaitu 4 informan yang menggunakan IUD dan 4 informan non- IUD, yang saat ini memilih menggunakan kontrasepsi tersebut, 7 informan yaitu 4 informan yang menggunakan IUD dan 3 informan non-IUD menjawab sudah nyaman dan aman, namun 1 informan non- IUD menjawab pernah mencoba dulu, 4 (empat) informan yang sudah menggunakan kontrasepsi IUD menjawab tidak, dengan alasan yang positif, berbeda dengan alasan yang diberikan informan non-IUD yaitu karena takut. Berbeda dengan hasil penelitian terdahulu.

Menurut penelitian Iram Barida Maisya (2014) bahwa seluruh informan yang menggunakan kontrasepsi IUD memiliki sikap yang positif terhadap kontrasepsi tersebut yang di tunjukan dengan perasaan tidak takut, nyaman, efektif dan setuju untuk digunakan pada wanita dengan usia $>35$ tahun.

Hal ini berkaitan dengan hasil wawancara bersama 8 informan yaitu 4 WUS yang menggunakan IUD dan 4 WUS non-IUD, dari hasil wawancara dengan 8 informan didapatkan hasil bahwa 4 informan IUD bersikap positif terhadap kontrasepsi IUD, berbeda halnya dengan 4 informan non-IUD bersikap negatif terhadap IUD dan menolak menggunkaan IUD dikarenakan takut. 


\section{Dukungan Suami}

Berdasarkan hasil wawancara dengan informan didapatkan 8 (delapan) informan yaitu 4 informan yang menggunakan IUD dan 4 informan non- IUD, saat di tanyakan mengenai dukungan suami dalam ber- kb, 8 (delapan) informan menjawab suami mereka mendukung.

Pertanyaan selanjutnya mengenai dukungan seperti apa yang suami informan berikan, 8 (delapan) informan memberikan jawaban bahwa suami mendukung untuk ber- KB, Pertanyaan terakhir dari variabel ini yaitu mengenai tanggapan suami informan saat memilih kontrasepsi yang digunakan saat ini, 7 dari 8 informan menjawab bahwa suami mereka membolehkan saja dengan alasan nyaman saat menggunakan kontrasepsi tersebut, namun 1 informan yang menggunakan IUD menjawab bahwa suami kurang setuju saat informan menggunakan kontrasepsi yang digunakan.

Menurut hasil penelitian terdahulu menurut Titik Kurniawati (2011) dikatakan bahwa dari hasil wawancara tentang hal hal yang berpengaruh dalam proses pengambilan keputusan untuk istri memilih kontrasepsi, didapatkan bahwa kesimpulan peran suami dalam hal kontrasepsi jarang sekali mendukung walaupun demikian suami harus tetap ikut adil dalam masalah KB dengan memberikan saran dan ikut memutuskan dalam pemilihan kontrasepsi yang akan di pakai.

Terlihat juga suami tidak mengantarkan istri untuk pergi ke pelayanan kesehatan dikarenakan kesibukan pekerjaan. Hal ini berkaitan dengan peran serta suami dan istri dalam hal $\mathrm{KB}$, didapatkan hasil wawancara bahwa peran suami berkaitan dengan dukungan yang diberikan suami saat istri akan memilih kontrasepsi sebagian besar mereka mengantar istri pergi ke pelayanan kesehatan untuk mendapatkan pelayanan KB dengan alasan dengan alsan kesibukan kerja, sebagian kecil ada yang bisa mengantar bila istri meminta untuk di antar. Suami hanya diam saja dalam urusan KB, namun bila istri mengalami keluhan karena pemakian kontrasepsi baru suami memberikan saran kepada istri agar pergi untuk periksa ke tenaga kesehatan.

\section{Sumber Informasi}

Berdasarkan hasil wawancara dengan informan didapatkan 8 informan yaitu 4 informan yang menggunakan IUD dan 4 informan non-IUD, pertanyaan yang diberikan yaitu pernahkah informan mendapat informasi mengenai kontrasepsi IUD, ke-8 informan menjawab pernah mendapatkan informasi mengenai kontrasepsi IUD. Pertanyaan peneliti selanjutnya untuk 8 informan yaitu 4 informan yang menggunakan IUD dan 4 informan non- IUD mengenai dari mana informan mendapat informasi IUD, ke-8 informan menjawab dari tempat pelayanan kesehatan dan dari tenaga kesehatan.

Pertanyaan selanjutnya untuk 8 informan yaitu 4 informan yang menggunakan IUD dan 4 informan non- IUD, mengenai tanggapan terhadap informasi yang di dapatkan, 7 dari 8 informan yang menggunakan kontrasepsi IUD maupun non-IUD menjawab jelas, bermanfaat, jelas dan sangat di mengerti dengan memberikan alasan yang postif, namun 1 informan nonIUD yang memberikan alasan negatif mengenai informasi tersebut dikarenakan informsi yang di dapat bersumber dari lingkungan sekitar seperti tetangga dan teman dan bersifat negatif.

Menurut penelitian Dhita Prasanti (2018), menyatakan bahwa seluruh informan yang menggunakan kontrasepsi menyatakan pendapat informasi mengenai kontrasepsi IUD dari 
dokter kandungan, selain itu mereka juga mendapat informasi dari sumber lain yaitu, buku dan internet. Sedangkan pada informan yang tidak menggunakan kontrasepsi IUD seluruhnya tidak mendapatkan informasi tentang kontrasepsi IUD dari bidan atau PLKB, ada yang hanya mendengar dari tetangga ada yang dari internet dan selebihnya belum pernah mendengar tentang IUD.

Hal ini berkaitan dengan hasil wawancara bersama 8 informan yaitu 4 WUS yang menggunakan IUD dan 4 WUS non-IUD, hasil wawancara dengan 8 informan didapatkan hasil bahwa 7 informan yaitu 4 informan IUD dan 3 informan non IUD, pernah mendapatkan informasi mengenai IUD, dan informasi yang mereka dapat berasal dari PLKB, Posyndu, Puskesmas dan Rumah sakit, hanya 1 informan non IUD yang mendapatkan informasi tersebut dari lingkungan sekitar atau tetangga, karrna informasi yang didapat bukan dari tenaga kesehatan atau ahlinya maka info tersebut menjadi salah dan menjadi suatu hal yang negatif.

\section{KESIMPULAN}

Berdasarkan hasil penelitian ini penulis dapat menyimpulkan bahwa Dari 8 wanita usia subur, terdapat 4 orang wanita usia subur yang menggunkaan kontrasepsi IUD dan memiliki pengetahuan cukup mengenai alat kontrasepsi IUD, dan 4 orang wanita usia subur yang menggunakan kontrasepsi namun bukan IUD diantaranya suntik, pil, steril, dan pil memiliki pengetahuan yang kurang mengenai alat kontrasepsi IUD. Dari 8 wanita usia subur, 4 WUS peserta IUD bersikap positif terhadap kontrasepsi IUD, namun 4 WUS bukan peserta IUD bersikap negatif terhadap kontrasepsi IUD.

Dukungan suami berperan penting untuk wanita usia subur menentukan kontrasepsi yang akan digunakan, dari 8 wanita usia subur mendapat dukungan dari suami, seperti dukungan mengantarkan, memperhatikan, mengingatkan serta memotivasi, namun saat ditanya mengenai tanggapan suami terhadap kontrasepsi yang di pergunakan saat ini oleh wanita usia subur 7 dari 8 wanita usia subur di berikan tanggapan yang postif oleh suami mereka, namun terdapat 1 wanita usia subur yang menggunakan kontrasepsi IUD yang mendapatkan tanggapan negatif dari suami mengenai kontrasepsi yang di pergunakannya saat ini.

Sumber informasi pun menjadi hal penting untuk pengetahuan wanita usia subur mengenai alat kontrasepsi sangat berhubungan dengan pengetahuan yang di dapatkan, karena bila sumber informasi yang di dapatkan itu jelas dan membawa hal positif akan berdampak baik juga pada pengetahuan yang di dapat di lingkungan masyarakat terutama wanita usia subur yang akan menentukan kontrasepsi yang akan di pakai, dari 8 wanita usia subur pernah mendapatkan informasi mengenai kontrasepsi IUD, dan dari 7 wanita usia subur mendapatkan infomasi tersebut 2 diantaranya mendapatkan informasi dari posyandu, 3 dari puskesmas, 1 dari rumah sakit, 1 dari plkb dan kader dan hanya 1 wanita usia subur yang mendapatkan informasi dari tetangganya yang memeberikan dampak yang negatif terhadap pengetahuan wanita usia subur.

\section{Saran}

Pelayanan KIE tidak hanya dilakukan pada saat posyandu saja, akan tetapi dilakukan pada forum tertentu, seperti pada saat arisan atau pengajian yang di laksanakan tiap 
minggunya. Karena menyangkut waktu ibu rumah tangga terutama WUS yang berada di wilayah yang tidak bisa menyempatkan waktu untuk pergi ke posyandu pada jam jam tertentu.

Ketika melakukan KIE mengenai kontrasepsi, sebaikknya peyuluh membawa alat (contoh dari alat kontrasepsi) agar akseptor KB paham dan tau alat kontrasepsi yang seperti apa yang akan mereka pergunakan.

Sebaiknya saat sedang melaksanakan KIE, PLKB harus bekerja sesuai dengan pekerjaan nya yaitu sebagai penyuluh KB yang harus mejelaskan kepada akseptor mengenai kontrasepsi yang akan di pilih, bukan seperti kader atau sesama akseptor yang saling menjelaskan, karena jika kader atau sesama akseptor menjelaskan apa yang mereka tau dan alami, dikhawatirkan informasi yang di dapat tidak sesuai dan akan berdampak menjadi rumor yang tidak baik.

\section{DAFTAR PUSTAKA}

Astuti, Eni. (2014). Deskriptf faktor-faktor yang mempengaruhi wanita usia subur (WUS) tidak menggunakan alat kontrasepsi. Jurnal ilmiah kebidanan.Vol.5. no. 2.Hal. 99-108.

Alfaih, Ismi Dzalifa. (2015). Faktor-faktor yang berhubungan dengan penggunaan metode kontrasepsi jangka panjang diwilayah kerja puskesmas Kecamatan Kalideres tahun 2015. (Skripsi). Jakarta: UIN Syarif Hidayatullah

Apriana, Bahtera Musa. (2012). Faktor- faktor yang berhubungan dengan pemakaian kontrasepsi implant pada akseptor di Puskesmas Ciomas Kecamatan Ciomas Kabupaten Bogor tahun 2012. (skripsi). Depok : Universitas Indonesia Fakultas Kesehatan Masyarakat Peminatan Kebidanan Komunitas Depok.

Adha, C. N., Prastia, T. N., \& Rachmania, W. 2019. Gambaran Status Gizi Berdasarkan Lingkar Lengan Atas Dan Indeks Massa Tubuh Pada Mahasiswi Fikes Uika Bogor Tahun 2019. Promotor, 2(5), pp 340-350. Retrieved 2019 from: http://dx.doi.org/10.32832/pro.v2i5.2523

Bakri, I., Sari, M. M., \& Pertiwi, F. D. (2019). Hubungan Dukungan Suami Dengan Pemberian Asi Eksklusif Di Wilayah Kerja Puskesmas Sempur Kota Bogor Tahun 2018. Promotor, 2(1), 27. https://doi.org/10.32832/pro.v2i1.1786

D. T. Agina, F. D. Pertiwi and I. Avianty, "Faktor - Faktor Yang Berhubungan Dengan Perilaku Penggunaan Vapor di Kalangan Siswa Sekolah Menengah Kejuruan Bina Sejahtera 2 Kota Bogor," PROMOTOR Jurnal Mahasiswa Kesehatan Masyarakat, vol. 2, no. 2, pp. 101-111, 2 April 2019.

Fartaeni, F., Pertiwi, F. D., \& Avianty, I. (2018). Hubungan Pengetahuan, Sikap dan Dukungan Suami Terhadap Pemberian ASI Eksklusif Di Desa Pabuaran Kecamatan Gunung Sindur. Healty Jurnal Kesehatan Masyarakat, 6(1). https://doi.org/10.32832/hearty.v6i1.1255

Fitrianingtyas, Pertiwi, dan Rachmania, W. Faktor-Faktor yang Berhubungan dengan Kejadian Kurang Energi Kronis (KEK) pada Ibu Hamil di Puskesmas Warung Jambu Kota Bogor. HEARTY Jurnal Kesehatan Masyarakat. 2018;6(2):1-8.

FA Lubis, W Rachmania, TN Prastia. (2020). FAKTOR-FAKTOR YANG BERHUBUNGAN DENGAN PENGGUNAAN METODE KONTRASEPSI JANGKA PANJANG (MKJP) PADA PESERTA KB AKTIF DI KELURAHAN MEKAR WANGI KECAMATAN TANAH SAREAL TAHUN 2019. PROMOTOR 3 (3), 251-258 
Hasanah, Siti Noor. (2017). Gambaran pemilihan kontrasepsi intra uterine device (IUD) pada pasangan usia subur (PUS) di Desa Sidoarjo Sleman Yogyakarta. (Skripsi). Yogyakarta: Universitas Aisyah Yogyakarta.

Kusnadi NR, Rachmania W, Pertiwi FD. Faktor-Faktor Yang Berhubungan Dengan Pemilihan Metode Kontrasepsi Suntik Pada Peserta KB Aktif Di Kelurahan Mekarwangi Kecamatan Tanah Sareal Kota Bogor Tahun 2019. Promotor. 2019;2(5):402-9.

Lwrance, W. Green, Marshall, W. Kreuter. (2005). Health Program Planning AN EDUCATIONAL APPROACH : Library of Congress Cataloging-in-Fublication Data.

Novina, Hartikasari. (2016). Hubungan pengetahuan ibu dengan penggunaaan alat kontrasepsi IUD di Puskesmas Payungrejo Kabupaten Lampung Tengah. (skripsi). Bandar Lampung : Fakultas Kedokteran Universitas Bandar Lampung 2016.

Mizna, Sabila. (2016), Gambaran perilaku wanita dalam penggunaan kontrasepsi di Pamulang, Kota Tangerang Selatan. Jurnal kesehatan reproduksi Vol 7, No, 3. (2016. PP. 185-197).

Marmi. (2016). Buku ajar pelayanan KB. Yogyakarta: pustaka belajar.

Oktavia, Dwita. (2018). Efektivitas intra uterine device (IUD) sebagai alat kontrasepsi. Lampung. Jurnal MAJORITI. Volume 5. Nomor 4. Oktober 2016: Fakultas kedokteran Universitas Lampung.

Pertiwi, F. D., Hariansyah, M., \& Prasetya, E. P. (2019). FAKTOR RISIKO STUNTING PADA BALITA DIKELURAHAN MULYAHARJA TAHUN 2019. PROMOTOR, 2(5). https://doi.org/10.32832/pro.v2i5.2531

Pertiwi, F. D., Rahman, R. M., \& Lestari, D. W. (2018). Pemberdayaan masyarakat melalui bidang literasi di Desawaru Jaya. Jurnal ABDI DOSEN: Jurnal Pengabdian Pada Masyarakat, 2(2), 129-137. https://doi.org/10.32832/abdidos.v2i2.170

Pertiwi FD, Isnawati. gambaran pengetahuan dan sikap ibu hamil tentang tanda bahaya kehamilan di Puskesmas Caringin Kabupaten Bogor tahun 2015. HEARTY Jurnal Kesehatan Masyarakat Vol.5 No.1 2017.

Pertiwi, F. D., \& Farihah, N. (2017). Hubungan Lingkungan Dengan Kejadian Infeksi Saluran Pernafasan Akut (Ispa) Pada Balita Di Wilayah Kerja Uptd Puskesmas Semplak Tahun 2016. Hearty, 5(2). https://doi.org/10.32832/hearty.v5i2.1056

Putri, Rani Pratama. (2017). Perbandingan faktor-faktor yang mempengaruhi penggunaan kontrasepsi intra uterine device (IUD) pada wanita usia subur (WUS) di Kecamatan Sukarame kota Bandar Lampang. (Skripsi). Bandar lampung: Universitas Lampung.

Prasanti, Dhita. (2018). Hambatan komunikasi dalam promosi kesehatan program keluarga berencana (KB) IUD di Bandung. Jurnal penelitian komunikasi dan opini public. Vol. 22. No. 1, juli 2018: 52- 63.

Prastia, T.N., Listyandini, R., (2020). Keragaman Pangan Berhubungan dengan Stunting Pada Anak Usia 6-24 Bulan. Hearty, 8(1)

Prastia, T. N. (2019). Gambaran Tekanan Darah Dan Indeks Massa Tubuh Pada Mahasiswa Prodi Kesmas Angkatan 2017 Fikes Uika Bogor Tahun 2018. Promotor, 2(3), 234-239.

Rachmania, W., Kurniawan, D., \& Pertiwi, F. D. (2019). Gambaran Tingkat Pengetahuan Tentang Implan Pada Wanita Usia Subur Di Kelurahan Katulampa Kecamatan Bogor Timur Kota Bogor. Hearty, 7(1), 1-11. https://doi.org/10.32832/hearty.v7i1.2304

Siti HS, Fenti DP, Ichayuen A. Gambaran Pengetahuan Orangtua, Dukungan Keluarga, Dan 
Status Imunisasi Terhadap Kejadian Difteri Pada Balita Di Wilayah Puskesmas Cileungsi Kabupaten Bogor Tahun 2018. Jurnal Mahasiswa Kesehatan Masyarakat. 2019.

Sulistya, Ari. (2014). Pelayanan keluarga berencana. Jakarta: Salemba medika.

Suratun, dkk. (2017). Pelayanan keluarga berencana dan pelayanan kontrasepsi. Buku kesehatan.

Sugiyono. (2017). Metodologi penelitian kuantitatif, kualitatif dan R\&D. Bandung. ALFABETA.

Solikhah, Siti. (2017). Gambaran pengetahuan wanita usia subur (WUS) tentang konytasepsi IUD di wilayah kerja puskesmas Danurejen 1 kota Yogyakarta tahun 2017. (karya tulis ilmiah). Yogyakarta: STIKES Jendral Ahmad Yani Yogyakarta.

Titik, Kurniawati. (2012), Studi kualitatif tentang pengambilan keputusan dalam pemilihan metode kontrasepsi pada WUS di Kota Semarang. Jurnal Vol. 1/ No 1/ Januari 2012.

TN Prastia, R Listyandini. 2020. Perbedaan Kadar Hemoglobin dan Lingkar Lengan Atas Ibu Hamil antara Anak Bawah Dua Tahun (BADUTA) Stunting dan Normal. Journal of Health Science and Prevention 4 (2), 100-105

Yulianingsih, Pratiwi Nurul. (2016). Gambaran pengetahuan dan sikap suami tentang alat kontrasepsi di Sususn soreang desa Jipang Kecamatan Botonompo Selatan Kabupaten Gowa tahun 2016. (Proposal karya tulis ilmiah). Makassar: Universitas Negri Alaudin Makassar. 